\title{
Risk-Sharing on the Labour Market: How to Treat Young Generations?
}

\author{
by Christian Gollier*
}

\begin{abstract}
The labour market has failed to spread risk among different generations. Unlucky generations entering the labour market during a recession bear almost all risks, whereas older workers are protected by implicit contracts offering a downward rigid wage. Using three two-period models with overlapping generations of workers, we analyze the conflict of interest between insiders with a contract and outsiders (unemployeds and the young cohort entering the labour market). The wage discrimination between generations will depend upon the incentive of insiders to raise the hiring wage. An intermediary wage discrimination is shown to be efficient in order to promote employment for outsiders, although limiting the cost of layoff for insiders.
\end{abstract}

\section{Introduction}

It is widely accepted that generations entering the labour markets since the mid 1970 s have faced serious economic problems. They are due to three sources. First, on the side of demand for labour, firms have engaged fewer young workers in response to the economic depression. Second, on the supply side, the entry of "baby boom" generations on the job market has depressed economic opportunities for these cohorts. Finally, the higher participation rate of women has also played a prominent part in the unemployment problem. Since this unemployment appears to be involuntary, the uncertainty about the evolution of these three sources of unemployment represents a considerable risk for present and future vintages of labour-suppliers.

Generations born under a lucky star get well-paid jobs and the implicit labour contract theory explains that they are able to protect themselves against future recessions. Specifically, they pay now an insurance premium (taking the form of lower wages) to receive a downward rigid wage in the future. This is combined with a relative employment security. But present unemployeds and future generations are excluded from this risk-sharing arrangement.

\footnotetext{
* Research assistant at the Center for Operations Research and Econometrics (CORE, Belgium). I am much indebted to Jacques Drèze and Mathias Dewatripont for helpful discussions. Research support from the "Fonds National de la Recherche Scientifique" is gratefully acknowledged.
} 
Hence, the labour market does not adequately spread risk among individuals. Risk sharing efficiency requires that any risk in the economy be shared among individuals in such a way that everybody charges the same risk premium for an additional share in each lottery. This property is clearly not fulfilled by any realistic labour market mechanism. As a matter of fact, different generations do not participate symmetrically in the negotiation about future wages and employment. In particular, generations-to-be are definitely not represented. The literature in print presents two theories which deal with this kind of problem: the implicit labour contract theory and the so-called "insider-outsider" model.

Holmstrom [1983] proposes a multiperiod equilibrium with long-term labour contracts in which new contracts stipulate wages that clear the labour market at every moment. At the current hiring wage, there is no disequilibrium, i.e. there is no involuntary unemployment. The main features of the long-term labour contracts equilibrium are that risk-neutral firms will protect their contractual employees against variation of the marginal value product of labour, yielding downward rigid wage for contractual workers. Firms get their return of the insurance deal by paying less than the marginal product to young workers. The difference between the marginal product and the wage is an insurance premium covering future labour revenues. A wage discrimination between employees under contract and new recruits will emerge in bad states. This discrimination equals the sum of the premium paid by newcomers and the indemnity paid by the firm to incumbent workers. When a depression is expected to arise soon, newcomers will prefer to increase the premium paid today, i. e. to reduce present hiring wages, in order to sustain their long-term contractual wage, i. e. to receive larger insurance payments in the future.

The most interesting illustration of this concerns two-tier labour contracts. Dewatripont [1986] gives some evidence for this kind of hiring wage flexibility in that country. Since 1983 , a number of unions have engaged in wage agreements where new recruits receive a different treatment relative to current workers. Under such "two-tier" schemes, 1987's hires are not just paid less than the 1986's. When their pay rises from the starting level, it will be less than what his predecessor was paid on the corresponding rung of the seniority ladder. Almost $25 \%$ of US non-construction union workers were covered by two-tier contracts. The concession of pilots in the American Airlines is an extreme example of the twotier scheme: the rate for new pilots was cut in half! In another sector, postal workers agreed for lower pay for new recruits ranging up to $30 \%$. General Motors, at one of its plants, gave members of the International Union of Electrical Workers lifetime contracts in exchange for a $45 \%$ pay cut for new recruits. During the period, it was argued that two-tier pay deals made economic sense because it will increase demand for labour: many workers have found a job, albeit at lower pay, that they otherwise would not have had.

Previous insider-outsider models (Lindbeck and Snower [1984a], [1984b], [1985a], [1985b], Solow [1985], Carruth and Oswald [1986]) pay attention to conflict of interest between workers under contract and those - new entrants to the labour force and others who are currently without a contract of any kind. The common feature of these models is that insiders are able to set their wages above the minimal wage at which outsiders would be willing to work, but the employers have no incentive to fire the insiders and hire outsiders.

The implicit contract theory is connected to this kind of analysis in the sense that senior workers (insiders) receive a higher wage than new workers (outsiders) for whom wages are 
determined by instantaneous labour market conditions. Both types of models are characterized by a wage discrimination between insiders and outsiders. Moreover, the implicit contract theory explains why wages for seasoned workers are downward rigid over time. To the contrary, it does not give any information about the wage stickiness observed for workers-to-be.

The basic purpose of the paper is to combine the wage formation for outsiders as it is proposed by the insider-outsider theory (that is to say, insiders determine the wage discrimination to be imposed to outsiders) with the wage formation for insiders which is described in the implicit labour contract theory. Specifically, I consider a multi-firm model with uncertainty on prices and technologies. Before the true state of nature is known, incumbent workers are provided with an insurance which protects themselves against variations of the competitive wage. I analyze different models in which insiders - who gather firm-specific unions - cooperate with their employer to impose a fixed hiring wage for outsiders. In the simplest model (Section 3), negotiations on hiring wages take place in a decentralized process. The question is to know whether insiders and employers are interested in sustaining the hiring wage over its competitive level. The answer is rather trivial in this setting: by reducing the hiring wage to its smallest value acceptable for newcomers, the coalition of insiders and employers maximizes its expected rent. The benefit of this strategy may then be shared among the members of the coalition as larger expected profits and senior wages. The wage discrimination between insiders and newcomers appears to be the expression of either the insurance covering retained insiders alone and the negotiation power belonging to incumbent workers. Increasing the wage discrimination is a way to cut firms' wage costs without asking unionized workers to accept lower pay. In doing so, firms respect the clause of the implicit insurance. Workers-to-be are in no position to argue. Notice that since the wage of the marginal worker is competitive, the level of employment is efficient despite the presence of unions.

The outcome of this model asks several questions. In particular, remark that laidoff insiders - as newcomers on the labour market - are not covered against fluctuations of the market clearing wage (severance payments are prohibited for moral hazard considerations). This could represent a considerable risk for unionized workers in periods of reorganization of the economy (high labour mobility). A centralized union - a case analyzed in Section 4would therefore be interested in sustaining the hiring wage over its market clearing level in expanding firms in order to offer a partial insurance to laidoff insiders from declining firms. Newcomers into the labour force also benefit by this clause. In such centralized hiring wage setting, a partial rigidity of the hiring wage will emerge. But a wage discrimination remains optimal because unions do not want to offer full insurance to unemployed workers. The reason comes from the presence of young workers who are assimilated to free riders to the insurance reserve: they receive an insurance indemnity (larger wage) without participating to the constitution of the insurance reserve.

Finally, I consider a model in which unions take into account of the outsiders'welfare when they set the hiring wage. A certain wage discrimination - smaller than in previous models - is shown to be optimal. Outsiders are confronted to the following dilemma: increasing the hiring wage in bad states directly reduces earning risks but it generates more unemployment. This indirect effect can overwhelm the direct impact, viz. a hiring wage increase can deteriorate the global outsiders' welfare. Insiders do not face such a dilemma 
because their volume of employment is protected by a job priority rule stipulated in the implicit labour contract. It results that outsiders have an additional incentive to reduce wages that insiders have not. A wage discrimination follows at the optimum. It will depend on both the elasticity of the labour demand and the workers' attitude toward risks.

\section{The model}

Consider a two-period model. Periods are indexed $t=0,1$. At the beginning of each period $t$, a new generation $t$ is born. Except generation 1, all people live for two periods, so at each point in time a young and an old generation live side by side.

The economy consists of $J$ firms, indexed $j=1, \ldots, J$. In each period the economy will be in one of $S$ mutually exclusive states $s=1, \ldots, S$. In the first period, it is known which states prevails, but the second period state is uncertain. Objective, or agreed-upon subjective probabilities, $p_{s} \geq 0, \sum_{s} p_{s}=1$, describe this uncertainty. It is convenient to distinguish both periods and state by the same index $s$, so let $s=0$ represent the first period.

Each firm produces one single good in both periods. It acts monopolistically on its market. Firms use labor as their single input. Production in state $s$ by firm $j$ is decribed by $q_{j s}\left(L_{j s}\right)$ where $L_{j s}$ is labor input. The inverse demand function for good $j$ in state $s$ is $p_{j s}\left(q_{j s}\right)$. Workers of generation $t$ in state $s$ are represented by a continuum $\left(0, n_{s}\right) ; n_{0}$ is the cohort size of generation 1 and $n_{s}$ the state-contingent size of generation 2 . In the first period, there are three sources of uncertainty for the second period; the productivity (function $q_{j s}$ ), the price (function $p_{j s}$ ) and the cohort size of the new generation $\left(n_{s}\right)$ are unknown. Risks are firm-specific. Notice that this model can also be viewed as a unicommodity competitive market model. This special case of the previous set-up arises when $p_{j s}^{\prime}=0$ for all $j$ and $s$ and $p_{i s}$ is independent of $j$. Hence, one can also interpret this model as describing a single industry with several firms (with different production functions).

The revenue of firm $j$ in state $s$ is $f_{j s}\left(L_{j s}\right)=p_{j s}\left(q_{j s}\left(L_{j s}\right)\right) q_{j s}\left(L_{j s}\right)$. It could more generally be interpreted as the profit excluding labor costs thereby accommodating uncertainties related to other inputs. I assume that $f_{j s}^{\prime}>0, f_{j s}^{\prime \prime}<0$, and $f_{j s}^{\prime}\left(L_{j s}\right) \rightarrow 0$ as $L_{j s} \rightarrow \infty$.

Firm owners, who are able to diversify risks on the capital market, are assumed to be risk-neutral. Their objective in the first period is to maximize the present expected value of profits:

$$
F_{j}=\Pi_{j 0}+i \sum_{s} p_{s} \Pi_{j s} \quad \forall j,
$$

where $\Pi_{j s}$ is the profit in state $s$ and $\delta$ is the discount factor.

Workers are endowed with one unit of labor in each period which they supply inelastically. There is no possibility to share work. If an individual does not work, he receives an exogenous indemnity $t_{s}>0$. Neither savings nor borrowing is allowed. Each worker will consume whatever he earns in each period. Leisure has no value (or that is included in $t_{s}>$ $0)$. The instantaneous utility function $u(w)$ is assumed to be increasing and concave $\left(u^{\prime}>0\right.$, $\left.u^{\prime \prime} \leq 0\right)$; i. e. workers are risk-averse. We also assume that $u^{\prime}(0)=+\infty$. 
In period 0 , firm $j$ has $\ell_{j 0}^{o l d}$ old workers (born at $\mathrm{t}=-1$ ) who are paid $w_{j 0}^{o l d}$. In the twoperiod model, $\ell_{j 0}^{\text {old }}$ and $w_{j 0}^{o l d}$ are assumed to be exogenous. Firms can also hire $\ell_{j 0}$ young workers in $t=0$. A first-period labor contract $C=\left(w^{i}, r\right)$ specifies a wage vector $w=\left(w_{0}\right.$, $\left.w_{l}^{i}, \ldots, w_{s}^{i}, \ldots, w_{s}^{i}\right)$ and a retention probability vector $r=\left(r_{1}, \ldots, r_{s}, \ldots, r_{s}\right), 0 \leq r_{s} \leq 1$. Hence, the implicit labor contract proposed by firm $j$ stipulates a wage $w_{j 0}$ received with certainty by young workers during the first period of their life and a state-contingent wage $w_{j s}^{i}$ in the second period. The probability that a worker in firm $j$ be laid-off is $1-r_{j s}$ if state s prevails. Severance payments are institutionally ruled out for moral hazard considerations: if laid-off workers are fully compensated, they will have little incentives to search a new job.

In the second period, firms may lay off $\left(1-r_{j s}\right) \ell_{j 0}$, or hire $\ell_{j s}$ additional workers depending on circumstances. If $s$ prevails, a labor contract for workers hired by firm $j$ in the second period is simply a wage $w_{j s}$ paid for one unit of labor. Individuals who do not work in the first period cannot insure against downturns in the future.

In contrast to Holmstrom [1983], I am concerned with disequilibrium situations on the labour market. I consider the following labor market mechanism: at the end of the first period, the state $s$ prevailing during the second period is announced. In some firms, some workers are laid off in accordance with their implicit labor contract. At the beginning of the second period, the new generation enters the job market. The number of workers who search a job at that moment is $\phi_{s}=\left(n_{0}-\sum_{j} \ell_{j 0} r_{j s}\right)+n_{s}$. From that moment, the labor lottery takes place and a number of individuals are hired at random by firms. We assume that firms do not discriminate among workers of different generations when they hire new recruits in the second period. Consequently, young people are not able to sign contingent labor contracts for the future with firms which do not employ them in the present. Since unemployeds of different generations have the same probability to find a job, the probability to be hired by firm $j$ is $\Phi_{j s}=\phi_{s}^{-1} \ell_{j s}$.

At the beginning of the second period, an unemployed has an expected utility

$$
u\left(w_{s}^{*}\right)=\sum_{j} \Phi_{j s} u\left(w_{j s}\right)+\left(1-\sum_{j} \Phi_{j s}\right) u\left(t_{s}\right),
$$

where $w_{s}^{*}$ is the certainty equivalent wage of the labor lottery taking place in state $s$. It is a function of $w_{j s}, \ell_{j 0} r_{j s}$ and $\ell_{j s}$, for $j=1, \ldots, J$. Variations of $w_{j s}, s=1, \ldots, S$ represent firm-specific risks for workers, whereas the flexibility of $w_{s}^{*}$ implies market risks. I assume that workers can quit in the end of the first period if they can obtain a higher certainty equivalent wage by calling on the second period labor lottery. Hence, the absence of involuntary servitude requires $w_{j s}^{i} \geq w_{s}^{*}, s=1, \ldots, S$. By the way, the hiring wage $w_{j s}$ cannot be less than the certainty equivalent wage $w_{s}^{*}$, otherwise unemployeds will not accept the job. This is a natural assumption if the hiring mechanism is sequential, each job being taken at random after the other. It is assumed that firms can hire how much they want at wage $w_{j s} \geq w_{s}^{*}$.

One further restriction is imposed on wage determination. It seems very natural to assume that wages for young workers cannot exceed the wage for older ones. One can argue that wage discrimination in favour of old workers is necessary to maintain a sufficient level of motivation and cooperation among workers of different generations. The constraint $w_{j s}$ $\leq w_{j s}^{i}$ so introduced in the model does not necessarily lead to a wage scale increasing with seniority, wages being compared at one time for different types of workers. If a wage discrimination emerges, it will necessarily be to the advantage of old workers. To conclude with this point, the constraints on the wage formation are $w_{s}^{*} \leq w_{j s} \leq w_{j s}^{i}$ for all $j$ and $s$. 
A contract $C=\left(w^{i}, r\right)$ provides the worker with expected utility:

$$
U\left(C, w^{*}\left(w, \ell_{0} r, \ell\right)\right)=u\left(w_{0}\right)+i \sum_{s} p_{s}\left\{u\left(w_{s}^{i}\right) r_{s}+u\left(w_{s}^{*}\right)\left(1-r_{s}\right)\right\}
$$

To clarify this labor market mechanism, the tree of all possible stories of an individual born at $t=0$ is depicted in Figure 1. $U\left(C_{j}, w^{*}\right)$ is the value of the lottery represented by the tree with root $w_{j 0} . w_{s}^{*}$ is the expected utility of the last lottery.

Figure 1: Tree for a worker of the first generation

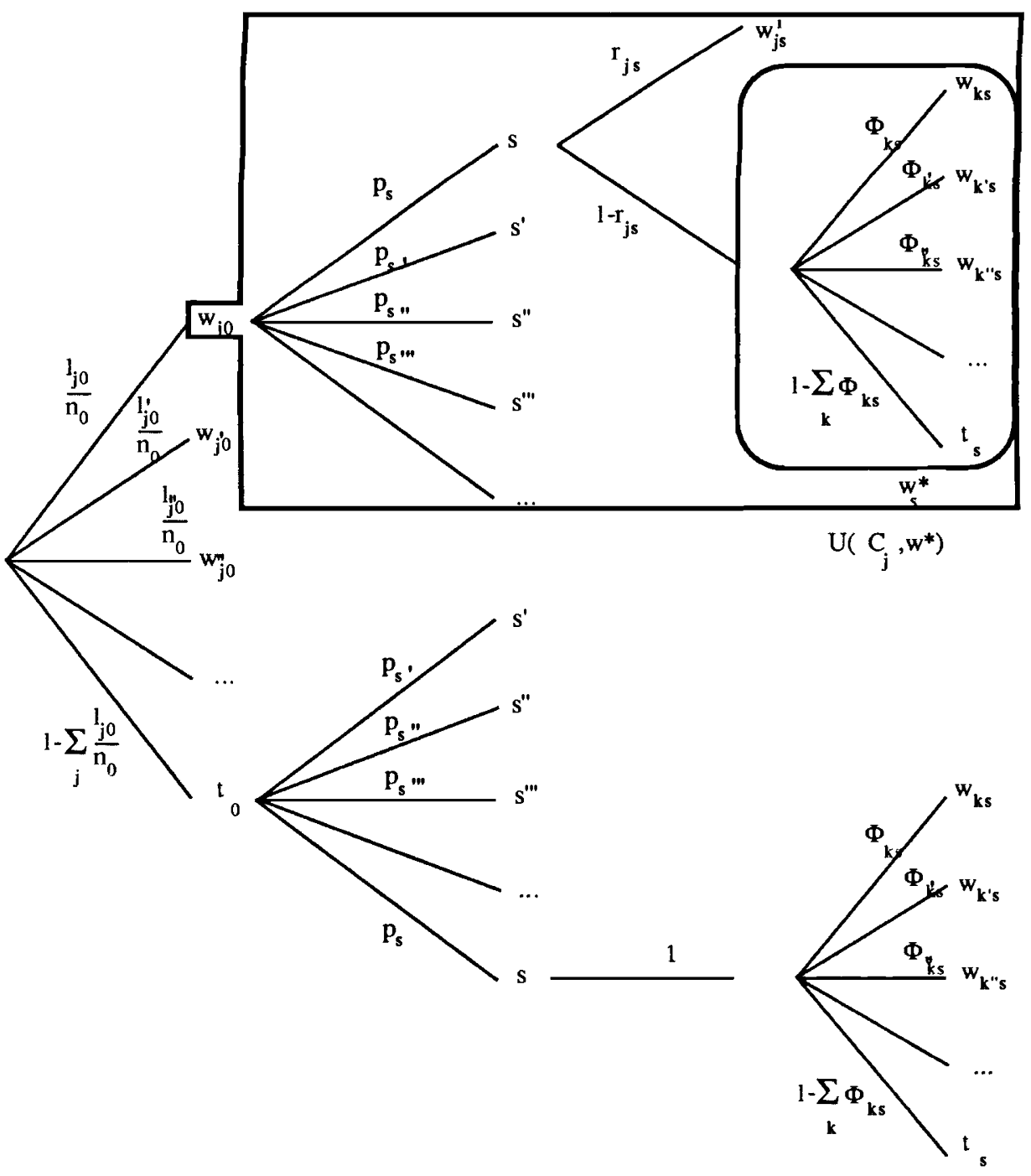


All young workers hired by firm $j$ in period 0 rally a firm-specific union which tries to maximize the sum of the expected utility of its workers. Old workers are not interested in participating in the union because wages are already fixed by an implicit contract established in period $t=-1$. The objective function of the union is

$$
U_{j}=\ell_{j 0} U\left(C_{j}, w^{*}\left(w, \ell_{0} r, \ell\right)\right) .
$$

With this formulation, notice that once everyone in the union $j$ has a job in the second period $\left(r_{j s}=1\right)$, the members are indifferent to increases in employment in the industry. This is not the case when $r_{j s}$ is less than one because laid-off unionized workers are interested in being engaged again by another firm in the industry. This is why $U_{j}$ is a function of $\ell_{k}, k=1, \ldots, J$. This is a difference with respect previous insider-outsider models.

I denote $\ell_{j s}^{r}=\ell_{j 0} r_{j s}$ the number of retained workers in state $s$ and $L_{j s}=\ell_{j s}^{r}+\ell_{j s}$ the total number of workers in the firm $j$, conditionally to $s$. Note that working experience does not influence skills since the output depends only upon the sum of the two types of workers. If at the optimum $w_{j s}^{i}=w_{j s}=w_{s}^{*}$, it will be seen that both the firm and the representative worker are indifferent between the employment of insiders or outsiders $\left(\ell_{j s}^{r}\right.$ and $\ell_{j s}$ are undetermined, only $L_{j s}$ will be determinate). To force unicity and avoid ambiguity, I shall adopt the convention that the firm will not substitute new recruits for old workers if both groups claim the same wage which is precisely equal to the certainty equivalent wage of the labour market:

$$
w_{j s}^{i}=w_{j s}=w_{s}^{*} \Rightarrow \ell_{j s}\left(1-r_{j s}\right)=0 .
$$

Finally, the analytical expressions of profit in both periods for firm $j$ are expressed by identities (4) and (5):

$$
\begin{aligned}
& \Pi_{j 0} \equiv f_{j 0}\left(\ell_{j 0}^{o l d}+\ell_{j 0}\right)-w_{j 0}^{o l d} \ell_{j 0}^{o l d}-w_{j 0} \ell_{j 0} \\
& \Pi_{j s} \equiv f_{j s}\left(\ell_{j 0}^{r}+\ell_{j s}\right)-w_{j s}^{i} \ell_{j s}^{r}-w_{j s} \ell_{j s .}
\end{aligned}
$$

A variable with an omitted index represents the vector of the corresponding variables. As an exemple, $w_{s}$ is the vector $\left(w_{1 s}, \ldots, w_{J s}\right)$.

\section{A decentralized cooperative market equilibrium}

In this section, we study a model where each firm negotiates wages and employment with its union, considering the result of negotiations at other firms as given. In this sense, the decision process is decentralized at the level of each firm, that is, there is no multiemployer arrangement.

I assume that the result of negotiations can be described by a cooperative equilibrium between the firm and its union of regular workers. Accordingly, the coalition of the firm and its cohort of young workers maximizes a weighted sum of the actual expected value of the firm $F_{j}$ and the corresponding total utility of contracts offered to young workers $U_{j}$. The relative weights used for this maximization are $\lambda_{1 j}$ and $\lambda_{2 j}$. The decision variables are the level of employment for the young generation and the terms of the implicit contract. Moreover, the coalition determines the wages at which the firm will hire new candidates in the second period and the number to be hired, for each state of the world. During the negotiations in firm $j, w_{k}$ and $l_{k}, k \neq j$, are viewed as exogenous parameters. If the $J$ coalitions are taken as players of a game, the resulting decentralized equilibrium can be seen as a Nash equilibrium. 
The definition of this equilibrium is introduced as follows:

DEFINITION 1: A decentralized cooperative equilibrium (DCE) is a set of $J$ vectors $\left(C_{j}, \ell_{j}, w_{j}\right), j=1, \ldots, J$, such that

(a) each vector $\left(C_{j}, \ell_{j}, w_{j}\right)$ is the solution of the maximization problem (6) taking the $J-1$ other vectors $\left(C_{k}, \ell_{k}, w_{k}\right)$ as given:

$$
\max _{C_{j}, \ell_{j}, w_{j}} W_{j}=\lambda_{1 j}\left[\Pi_{j 0}+\delta E\left[\Pi_{j s}\right]\right]+\lambda_{2 j} \ell_{j 0} U\left(C_{j}, w^{*}\left(w, \ell_{0} r, \ell\right)\right)
$$

subject to $\forall s: \quad(i) 0 \leq r_{j s} \leq 1$,

$$
\begin{aligned}
& \text { (ii) } w_{s}^{*} \leq w_{j s}, \\
& \text { (iii) } w_{j s} \leq w_{j s}^{i}, \\
& \text { (iv) } \ell_{j s} \geq 0 \\
& \text { (v) } w_{s}^{*}=w_{j s}=w_{j s}^{i} \Rightarrow \ell_{j s}\left(1-r_{j s}\right)=0,
\end{aligned}
$$

(b) the certainty equivalent wage $w^{*}\left(w, \ell_{0} r, \ell\right)$ is such that:

$$
u\left(w_{s}^{*}\right)=\sum_{j} \frac{\ell_{j s}}{n_{0}+n_{s}-\sum_{k} \ell_{k s}} u\left(w_{j s}\right)+\left(1-\sum_{j} \frac{\ell_{j s}}{n_{0}+n_{s}+\sum_{k} \ell_{k s}}\right) u\left(t_{s}\right),
$$

(c) total employment does not exceed the size of the active population:

$$
\sum_{j} l_{j 0} \leq n_{o} \quad \text { and } \quad \sum_{j} L_{j s} \leq n_{o}+n_{s} .
$$

The first-order conditions of program (6) are in Appendix A. In fact, the DCE problem looks like the long-term labour contract model analyzed by Holmstrom [1983]. Holmstrom assumes that the labour market is competitive at every moment so that each firm takes $w_{j s}$ and $w_{s}^{*}$ as given (specifically, all hiring wages $w_{j s}$ are just equal to $w_{s}^{*}$ and this latter variable is fixed at a level which clears the labour market). Alternatively, we investigate a case in which the hiring wage is chosen by the employers and the trade union. Except for this variable, we obtain the same results as in the Holmstrom's model. Accordingly, one can derive the following properties from the first-order conditions of the DCE model: first, the wages for workers under contract are downward rigid since

$$
w_{j s}^{i}=\max \left(w_{j 0}, w_{j s}\right) .
$$

The reason is that a risk-averse worker wants to be fully insured against wage variations when the insurance premium is actuarially fair as in the case of this framework. Full insurance for workers is clearly the efficient risk-sharing allocation since capital-owners are assumed to be neutral towards risks. The upward flexibility is due to constraint (iii) which forbids a wage discrimination to the advantage of the young generation. If the hiring wage in the second period is larger than the first period wages, it is not possible any more to implement full rigidity and any increase of the former has to be combined with the same increment of the second period contractual wages for regular workers. This is a second-best risk-sharing arrangement since a risk-averse individual will prefer a state-independent wage for the second period. The incentive compatibility constraints (ii) and (iii) forbid this solution. 
Second, the insurance contract offered by firms to their workers under contract also includes the form of an overemployment clause in periods of low demand. That is, when there exists a risk for insiders (workers under contract) to be laid off, the firm will accept to employ more workers than the number which maximizes its profit. Specifically, layoffs occur only when the marginal value product of labour satisfies the following property:

$$
\begin{gathered}
f_{j s}^{\prime}\left(L_{j s}\right)=g^{D C E}\left(w_{j s}^{i}, w_{j 0}, w_{s}^{*}\right) \stackrel{\text { def }}{=} w_{j s}^{i}-\frac{u\left(w_{j s}^{i}\right)-u\left(w_{s}^{*}\right),}{u^{\prime}\left(w_{j 0}\right)} \\
\text { whenever } 0<r_{j s}<1 .
\end{gathered}
$$

It can be shown that $g^{D C E}$ is always less than $w_{s}^{*}\left(\leq w_{j s}^{i}\right)$. In this sense, this phenomenon is called "labour hoarding" since the marginal value product of labour is less than both the observed wage in the firm and the certainty equivalent wage of the market whenever $r_{j s}<1$. The intuition behind this feature lies in the impossibility of severance pay for laid-off insiders. Moreover, it is easily shown from (9) that the labour hoarding device is used more intensively when the layoff cost for insiders increases, i. e. when the gap between $w_{j s}^{i}$ and $w_{s}^{*}$ becomes large. At the other extreme, when $w_{j s}^{i}$ is just equal to $w_{s}^{*}$, there is no cost to be laidoff (layoffs are voluntary) and $f_{j s}^{\prime}\left(L_{j s}\right)$ equals $w_{s}^{*}$. In such a case, there is no labour hoarding in firm $j$. To summarize, the labour contract offered to the first generation embodies two elements of risk-sharing: it includes a form of income insurance through downward wage rigidity and a relative job security offered by the labour hoarding strategy.

Third, the insurance benefits for insiders $\left(w_{j s}^{i} \geq w_{s}^{*}\right.$ and $\left.w_{s}^{*} \geq f_{j s}^{\prime}\right)$ need compensation for the firm. As in Holmstrom [1983], this compensation takes the form of an insurance premium paid out during the first period to enjoy the risk-sharing arrangement during the second period. This is an actuarial premium since the firm, which plays the role of insurer, is risk-neutral. The premium is equal to expected indemnities paid in the second period.

Since we have a cooperative equilibrium between the employer and its insiders, the equilibrium wage for insiders in the first period is a function of the relative negotiation power of the firm and its union. Specifically, $w_{j 0}$ equals $\omega_{j}$ where

$$
\omega_{j} \stackrel{\text { def }}{=} u^{\prime}-1\left(\frac{\lambda_{1 j}}{\lambda_{2 j}}\right) \text {. }
$$

It depends only upon the relative negotiation power of the firm and its union. In particular, it is independent of the marginal revenue of labour. To be consistent, $w_{j 0}$ is hereafter assumed to be larger than $t_{0}$, the reservation wage in period 0 .

One can now turn to the point of determining the optimal degree of wage discrimination between insiders and newcomers in period 1 . Since $w_{j s}^{i}$ is already determined by equation (8), there remains to choose the hiring wage $w_{j s}$. A variation of the hiring wage in period 1 has two effects on the objective of negotiators of firm $\mathrm{j}$. A reduction in $w_{j s}$ has a positive effect on the wage cost of the firm, but it has a negative impact on the cost of being laid-off since $\partial w_{s}^{*} / \partial w_{j s} \geq 0$. At first sight, a variation of $w_{j s}$ has a mitigated effect on the objective of the negotiators. However, it turns out that the equilibrium wages discrimination will always be maximum when there is unemployment.

PROPOSITION 1: In a decentralized cooperative equilibrium, all unemployment is voluntary and the discrimination is maximal whenever some individuals are unemployed, viz.

$$
w_{j s}=t_{s}=w_{s}^{*} \quad \forall s \text { such that } L_{j s}<n_{0}+n_{s} .
$$


This Proposition is proved in Appendix A. We present here an intuitive explanation for this result. The intuition is based on three points:

(a) If $w_{s}^{*}$ is taken as given by each firm, it is always optimal to reduce $w_{j s}$ until $w_{s}^{*}$ is reached. The reason is that if $\partial w_{s}^{*} / \partial w_{j s}$ vanishes, the only effect of a reduction in the hiring wage on $W_{j}$ is to increase the profit of firm $j$. It is in the interest of adult workers to have a large number of youths employed at low wages, as the employer's profit from youth labour may be, and is, used to subsidise an increase in the welfare of the first generation. Consequently, the equilibrium wage discrimination is maximal: $w_{j s}=w_{s}^{*}$. Nevertheless, there is one negative effect of this strategy for union workers: if all firms decide to reduce as much as possible their hiring wage, it will result that the certainty equivalent wage for a laid-off worker at the end of period $0\left(w_{s}^{*}\right)$ falls to the reservation wage $t_{s}$. This in turn implies a loss of expected utility for the union.

(b) If the labour contract stipulates that the firm will never hire newcomers and fire some insiders at the same time, whatever the wage discrimination is, then $w_{s}^{*}$ can actually be taken as a constant by the firm and its cohort of insiders. Intuitively, suppose for simplicity that the labour market in the second period is composed of only one firm and its union. In this case, the only way to protect laid-off workers against low $w_{s}^{*}$ is to hire additional workers at wages larger than the reservation wage. But this contradicts the condition just outlined if the firm fires workers at the same time. Analytically, we can derive from equations (2) and (7) that

$$
\frac{\partial U_{j}}{\partial w_{j s}}=\delta p_{s} \ell_{j 0}\left(1-r_{j s}\right) \ell_{j s} \phi_{s}^{-1} \mathbf{u}^{\prime}\left(w_{j s}\right)
$$

so that $\partial U_{j} / \partial w_{j s}=0$ whenever $\left(1-r_{j s}\right) \ell_{j s}=0$ which is just condition (b). That is, when the replacement of insiders by outsiders is forbidden, a particular firm has no means to insure its insiders against low $w_{s}^{*}$. In other terms, the impact of increasing $w_{j s}$ on $w_{s}^{*}$ will never benefit members of $\ell_{j 0}$.

(c) In fact, it is never efficient to hire newcomers and lay off some insiders at the same time, whatever the wage discrimination is. Replacing old workers by younger ones could, a priori, be interesting in case of a considerable wage discrimination vis-à-vis insiders. The crucial motive usually heard is to decrease wage costs and hence improve the profitability of the firm. In addition, it should be observed that it increases the certainty equivalent wage of laid-off workers. To be more explicit about this last point, suppose that $d \ell_{j s}=-\ell_{j 0} d r_{j s}>0$ (replacement of seasoned workers by unemployed workers). Despite the fact that we keep constant the number of employed workers in $\mathrm{j}$, it is easy to show that there is a positive effect on $w_{s}^{*}$ :

$$
d w_{s}^{*}=\phi_{s}^{-1}\left(1-\sum_{j} \Phi_{j s}\right) \frac{u\left(w_{j s}\right)-u\left(t_{s}\right)}{\mathrm{u}^{\prime}\left(w_{s}^{*}\right)} d \ell_{j s} \geq 0
$$

The replacement impact on the unemployeds' expected utility increases with the rate of unemployment (of course, it will be zero if $w_{j s}=t_{s}$ ). Nevertheless, the impact of the replacement on profits and on the certainty equivalent wage in case of lay-off is overwhelmed by the effect on the increasing lay-off risk $\left(d r_{j s}<0\right)$. Specifically, the replacement strategy decreases the expected utility of the contract offered to the firstperiod union workers. There is only one exception where the negotiators are different 
between insiders and newcomers in period 2. This is when $w_{s}^{*}=w_{j s}=w_{j s}^{i}$. Clearly in this case, a laid-off worker enjoys the same expected utility $u\left(w_{s}^{*}\right)$ as a retained worker with utility $u\left(w_{j s}^{i}\right)$. The firm $j$ is also indifferent since wage costs are equal for both types of workers. By condition (v), the preference is institutionally given to insiders. Notice that the condition $w_{j s}=w_{j s}^{i}$ is not sufficient to have this indifference since the risk-sharing include a labour hoarding clause which gives a certain protection to insiders against offers from outsiders. In conclusion, firms will not replace workers under contract by new recruits even when hiring wages are less than those currently paid to insiders. Since risk-averse workers are retained beyond the point of productive efficiency, marginal product is so low when firms begin to lay off that it will not be willing to hire, even at a very low hiring wages. Competition between workers under contract and out-of-work people is virtually shut off. This feature is obtained without assuming any productivity gap among people of different generations (as in Solow [1985]), or any hiring and firing costs (as in Lindbeck and Snower [1984a]).

Consequently, Proposition 1 follows: even if the demand side of the labour market has an atom, i.e. if there is a firm which is able to influence the level of $w_{s}^{*}$, no employer is able to offer an insurance to their own workers against a low certainty equivalent wage in case of layoff. Because of the totally decentralized bargaining assumption, a firm-specific union has no mean ot maintain $w_{s}^{*}$ at a sufficiently high level to protect its workers against low expected utility in case of firing.

It remains to analyze the full employment case. From the discussion above, the reader should be convinced that the following allocation is a DCE equilibrium: there exists a unique hiring wage $w_{s}^{*}$ in the economy. When there is unemployment, it is equal to $t_{s}$, the minimum wage, and all unemployment is voluntary. Notice that employed insiders are strictly better off than unemployeds. Once full employment occurs, the competition among prosperous firms will push the hiring wage rate above and $w_{s}^{*}$ will be fixed by the binding condition $\sum_{j} L_{j s} \leq n_{0}+n_{s}$. If the market clearing wage is less than the insiders'wage, some discrimination remains. But if the competition becomes harder, the discrimination will

Figure 2: Wages as a function of the employment rate (Decentralized cooperative equilibrium)

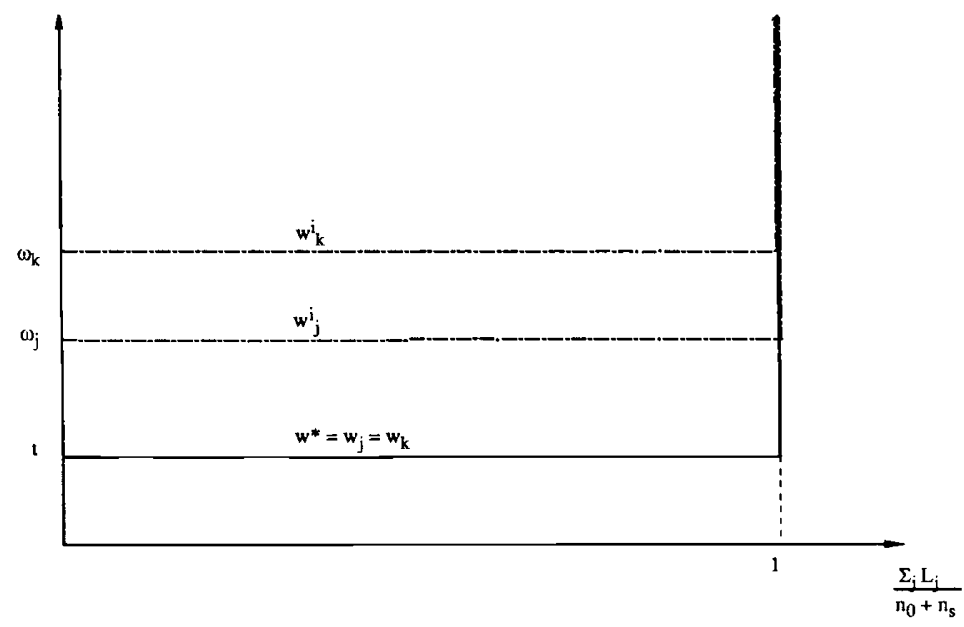


vanish and the wage for insiders will also be pushed above, as shown by (8). The DCE equilibrium exhibits fully flexible hiring wages combined with a downward rigid wage system for workers under contract, as shown in Figure 2.

If firm-specific unions cooperate with each other, and if risks are not correlated between firms, the story becomes quite different. Typically, it is possible to receive more than the reservation wage $t_{s}$ if laid-off because other more prosperous firms could accept to hire at a higher wage rate than $t_{s}$. In a centralized union model, the union can induce prosperous firms to accept to increase their hiring wage for laid-off union workers from other firms. This is impossible in the DCE model because each firm-specific union is interested only in its own workers'welfare. The centralized union model is analyzed in the next section.

Finally, I turn to the problem of existence and uniqueness of the DCE. Program (6) is a nonconcave programming problem since neither $\Pi_{j s}\left(C_{j}, w_{j s}, \ell_{j 0}, \ell_{j s}\right)$ nor $U\left(C_{j}, w^{*}\right)$ is concave. Nevertheless, it is possible to prove that the Pareto-frontier for this new problem is concave. Consequently, we obtain Proposition 2.

\section{PROPOSITION 2: There exists a unique DCE.}

Proof: Taking $w_{j s}=w_{s}^{*}$ as an exogenous variable in the maximization (6), Holmstrom [1983] showed that program (6) has a unique solution. Replace $w_{j s}$ and $w_{s}^{*}$ by the market clearing wage. The reader can verify that this wage exists since $\partial l_{j s} / \partial w_{j s}$ is negative. Then the solution obtained by Holmstrom is the unique DCE. This completes the proof.

However, it may not be desirable to let wages fall to the market clearing level during a recession. First, risk-sharing arrangements for future generations are ruled out in the first period. Therefore, young workers bear almost all the recession risks in the second period since the first generation is insured against future slumps. Secondly, wage discrimination by hiring date goes against accepted ethical norms of equal wage for equal work. Finally, it is not acceptable for the coalition of the firm and its union to let hiring wages drop to a very low level. For otherwise new firms could hire at this small wage and outbid established firms on their product market. This will reduce further their employment. This explanation of a hiring wage rigidity has been given by Drèze [1986]. In section 4 and 5 , we give other reasons for the existence of a certain degree of wage rigidity for newcomers.

\section{A centralized cooperative market equilibrium}

Let us now consider the situation when the wage and employment negotiations are centralized: there is only one union which brings together first-period employees of all firms, except old workers for whom wages are regulated by previous labour contracts. This union negotiates with the coalition of employers about wages and employment for both periods. The outcome of the negotiation is assumed to be a cooperative equilibrium with weights $\lambda_{1}$ and $\lambda_{2}$.

The centralized cooperative equilibrium is defined as follows:

DEFINITION 2: A centralized cooperative equilibrium (CCE) is a set of $J$ vectors $\left(C_{j}, \ell_{j}\right.$, $\left.w_{j}\right), j=1, \ldots, J$, which are solution of the program (8): 


$$
\begin{aligned}
& \max _{C, \ell, w, w^{*}} \sum_{j} W_{j}=\lambda_{1} \sum_{j}\left[\Pi_{j 0}+\delta E\left[\Pi_{j s}\right]\right]+\lambda_{2} \sum_{j} \ell_{j 0} U\left(C_{j}, w^{*}\right) \\
& \text { subject to } \forall j, s: \quad(i) 0 \leq r_{j s} \leq 1 \text {, } \\
& \text { (ii) } w_{s}^{*} \leq w_{j s} \text {, } \\
& \text { (iii) } w_{j s} \leq w_{j s}^{i} \\
& \text { (iv) } \ell_{j s} \geq 0 \text {, } \\
& \text { (v) } \sum_{j} \ell_{j 0} \leq n_{0} \text { and } \sum_{j} L_{j s} \leq n_{0}+n_{s} \text {, } \\
& \text { (vi) } w_{s}^{*}=w_{j s}=w_{j s}^{i} \stackrel{j}{\Rightarrow} \ell_{j s}\left(1-r_{j s}\right)=0 \text {, } \\
& (v i i) u\left(w_{s}^{*}\right)=\sum_{j} \Phi_{j s} u\left(w_{j s}\right)+\left(1-\sum_{j} \Phi_{j s}\right) u\left(t_{s}\right) \text {, } \\
& \text { (viii) }\left(f_{j s}^{\prime}\left(L_{j s}\right)-w_{j s}\right) \ell_{j s}=0 \text {. }
\end{aligned}
$$

In the second period, we constrain firms to have a profit-maximizing level of hiring, ie. the marginal value product of labour is just equal to the hiring wage whenever firm $j$ hires some additional workers (constraint (viii)). The motivation for the introduction of such constraint is to avoid the unrealistic feature about the equilibrium that we obtained in an earlier draft of the paper. Specifically, if no such constraint is introduced into the model, it could be shown that it is efficient for the negotiators of the centralized bargaining unit to engage in an "over-hiring" strategy in the sense that $f_{j s}<w_{j s}$ at equilibrium. Trade unions should induce expanding firms to hire more in order to offer more job opportunities to laidoff union workers from other firms. This strategy seems to be rather impractical due to the accepted common assumption in this literature that trade unions only control wage rates, not the employment level.

The necessary conditions of the CCE model are written in Appendix B. The fundamental difference with respect to the previous decentralized model is that several firms in a particular industrial sector can cooperate to limit the risk of a too low certainty equivalent market wage during the second period. This is done by a multi-firm arrangement where prosperous firms will hire at a wage larger than the clearing level to sustain the certainty equivalent wage of unionized laid-off workers. Involuntary unemployment and wage stickiness will then emerge. Before adressing this question, observe that the main characteristics of the implicit labour contracts for insiders proposed in the DCE model remain valid here: downward wage rigidity for workers under contract, labour hoarding in bad states and existence of an insurance premium paid by insiders during the first period of their life.

The first difference with respect to the previous model is that the first-period wage for workers under contract is independent of the firm. Specifically, we have

$$
w_{j 0}=\omega \stackrel{\operatorname{def}}{=} u^{\prime}-1\left(\frac{\lambda_{1}}{\lambda_{2}}\right) \text {. }
$$

This is a consequence of the simplifying assumption that each industry has the same weight in the negotiation and that $U$ is additive with no saving opportunities for workers. At equilibrium, it results that the insiders'wage is the maximum of $\omega$ and $w_{j}$. But the most important difference concerns of course the optimal strategy in terms of hiring wage rates. This is expressed in Proposition 3 which is proved in Appendix B. 
PROPOSITION 3: In a centralized cooperative wage setting mechanism, if there is wage discrimination and unemployment, hiring wage rates are such that:

$$
w_{j s}=\max \left(w_{s}^{*}, w_{j s}^{h}\right)
$$

where $w_{j s}^{h}$ is implicitly defined by the following equation:

$$
\begin{gathered}
u^{\prime}\left(w_{j s}^{h}\right)=\gamma_{s} u^{\prime}(\omega)+\left|\tilde{\eta}_{j s}\right| \frac{u\left(w_{j s}^{h}\right)-u\left(t_{s}\right)}{w_{j s}^{h}}, \\
\text { with } . \tilde{\eta}_{j s}=\frac{w_{j s}^{h}}{\ell_{j s}} \frac{d \ell_{j s}}{d w_{j s}}=\frac{w_{j s}^{h}}{f_{j s}^{\prime} \ell_{j s}} \leq 0, \\
\left.. \gamma_{s}=\frac{\phi_{s}-\sum_{k \in K_{s}} \ell_{k s}\left[u^{\prime}\left(w_{s}^{*}\right)+\tilde{\eta}_{k s} \frac{u\left(w_{s}^{*}\right)-u\left(t_{s}\right)}{w_{s}^{*}}\right]}{\sum_{k} \ell_{k 0}\left(1-r_{k s}\right)-\sum_{k \in K_{s}} \ell_{k s} u^{\prime}(\omega)}\right] \\
. K_{s}=\left\{k \mid w_{k s}=w_{s}^{*} \text { at equilibrium }\right\} .
\end{gathered}
$$

Proposition 3 indicates that any level of wage discrimination (and, in particular, no wage discrimination at all if $w_{j s}^{h}>\omega$ ) can be observed at equilibrium depending on variables such as the unemployment rate or the elasticity of the demand for labour $\tilde{\eta}_{j s}$ (more precisely, $\tilde{\eta}_{j s}$ is the elasticity of hirings with respect to the hiring wage). Further analysis and interpretation prove very difficult at the level of generality used so far. This is why we analyze a simplified model. Let us first define

$$
q_{s}=\frac{\sum_{k} \ell_{k 0}\left(1-r_{k s}\right)}{n_{0}+n_{s}-\sum_{k} \ell_{k 0} r_{k s}} \leq 1
$$

which is the proportion of laid-off insiders among all individuals looking for a job at the beginning of the second period. It is also the probability that an additional hiring be profitable for the self-interested union of insiders rather than for an outsider. The Corollary concerns an economy in which the elasticity of hirings is equal from one firm to the other, $\operatorname{viz} \forall j: \tilde{\eta}_{j s}=\tilde{\eta}_{s}$. Then, define $w_{s}^{h}$ as

$$
\mathbf{u}^{\prime}\left(w_{s}^{h}\right)=u^{\prime}(\omega) q_{s}^{-1}+\left|\tilde{\eta}_{s}\right| \frac{u\left(w_{s}^{h}\right)+u\left(t_{s}\right)}{w_{s}^{h}} .
$$

We will also assume that $t_{s}$ is sufficiently small, so that the solution $w_{s}^{h}$ of equation (17) is larger than $t_{s}{ }^{1}$. Then, equation (17) and the concavity of $u($.$) imply that w_{s}^{h}$ is smaller than $\omega$. The proof of the Corollary can be found in Appendix B.

Corollary: If the elasticity $\tilde{\eta}_{j s}$ is firm-independant, the centralized cooperative equilibrium has the following properties when there is unemployment:

$\forall j: \quad(i)$ insiders'wages are rigid: $w_{j s}^{i}=\omega$,

(ii) wages are discriminated: $w_{j s}=w_{s}^{h}<w_{j s}^{i}$.

\footnotetext{
${ }^{1}$ Otherwise, the hiring wage is fixed at $t_{s}$, the minimum wage.
} 
The CCE proposes larger spot wages than the DCE for which the wage for new recruits falls to the reservation wage. Here, the hiring wage can be maintained at a substantially higher level when $t_{s}$ is low. It results that $w_{j s}=w_{s}^{h}<w_{j s}^{i}=w_{j 0}$. In consequence, two observations should be pointed out: first, a downward rigidity for hiring wages emerges and, second, the wage discrimination between generations is less considerable than in the DCE. Furthermore, there might be involuntary unemployment in the second period in the sense that the hiring wage might be larger than the reservation wage. The partial wage rigidity emerging from equation (17) is a tool to achieve a certain wage protection against low earnings in case of firing of insiders in declining firms. The insurance takes the form of higher wage rates in the second period.

To understand the properties of the equilibrium, one can approximate equation (17) by using a second-order Taylor expansion of $u\left(t_{s}\right)$ around $u\left(w_{s}^{h}\right)$. It follows that

$$
u^{\prime}\left(w_{s}^{h}\right)=u^{\prime}(\omega) q_{s}^{-1}+\left|\tilde{\eta}_{s}\right|\left[\frac{w_{s}^{h}-t_{s}}{w_{s}^{h}}-\frac{\left(w_{s}^{h}-t_{s}\right)^{2}}{2 w_{s}^{h}} \frac{u^{\prime \prime}\left(w_{s}^{h}\right)}{u^{\prime}\left(w_{s}^{h}\right)}\right] u^{\prime}\left(w_{s}^{h}\right)
$$

Assuming hereafter that $t_{s}=0$ and using the relative Arrow-Pratt risk aversion index $R_{s}^{r}=-$ $\frac{w_{s}^{h} u^{\prime \prime}\left(w_{s}^{h}\right)}{u^{\prime}\left(w_{s}^{h}\right)}$, we obtain the following simplified formula:

$$
\begin{aligned}
u^{\prime}\left(w_{s}^{h}\right) & =\frac{n_{0}+n_{s}-\sum_{k} \ell_{k 0} r_{k s}}{\left(\sum_{k} \ell_{k 0}\left(1-r_{k s}\right)\right)\left(1-\left|\tilde{\eta}_{s}\right|\left(1+\frac{R_{s}^{r}}{2}\right)\right)} u^{\prime}(\omega) \\
& =\frac{u^{\prime}\left(w_{j s}^{i}\right)}{q_{s}\left(1-\left|\tilde{\eta}_{s}\right|\left(1+\frac{R_{s}^{r}}{2}\right)\right)}
\end{aligned}
$$

From equation (18), one can see that four elements influence the wage discrimination by hiring dates when some unemployment persists:

(i) The first point concerns the trade-off between the welfare of a cohort and its relative size:

$$
\frac{\partial w_{s}^{h}}{\partial n_{s}}=-\left[R_{s}^{a}\left(n_{0}+n_{s}-\sum_{k} \ell_{k 0} r_{k s}\right)\right]^{-1}<0
$$

where $R_{s}^{a}=R_{s}^{r} / w_{s}^{h}$, the absolute Arrow-Pratt risk aversion index. From empirical analysis, it appears that a large cohort size tends to have a negative effect on the relative earnings of its members, see Bloom and Freeman [1986] for a survey of this question. ${ }^{2}$ The intuition about the sign of this derivative is quite simple. Since firms cannot discriminate among workers of different generations, when they hire workers during the second period, young people will also benefit from this insurance. But the larger the

2 This observation is consistent with our model since (19) indicates that the hiring wage decreases when the size of the cohort increases. A crude estimation of the elasticity of the hiring wage rate to the cohort size is written as: $\tilde{\eta}_{w s}^{h}, n_{s}=-n_{s}\left[R_{s}\left(n_{0}+n_{s}-\sum_{k} \ell_{k 0} r_{k s}\right)\right]^{-1}$. For reasonable values of $n_{s} / n_{0}$ $+n_{s}-\sum_{k} \ell_{k 0} r_{k s}$, like one or so, and of $R_{s}^{r}$ like 3 to 6 (see Drèze [1981]), that elasticity goes around $0.15 \ldots-0.35$. This range of values corresponds to the empirical estimation of Bloom and Freeman [1986]. 
young cohort size is, the less unions will try to insure workers against having a too low expected wage if being laid-off (if $n_{s}$ tends to infinity, $w_{s}^{h}$ tends to 0 and therefore $w_{j s}$ will equal $t_{s}$, the minimum wage). This is because old workers do not want to share insurance benefit with a larger and larger young cohort which cannot contribute to the insurance reserve. Therefore "baby boom" cohorts will pay for their size by incuring lower wages. Unlucky generations will observe a reduction in their earnings because of the increasing reluctance of older generations to insure them against bad states of the world.

(ii) I analyze here the impact of the general economic situation on $w_{s}^{h}$. From equation (18), one can derive

$$
\frac{\partial w_{s}^{h}}{\partial \Sigma_{k} \ell_{k 0} r_{k s}}=-\frac{q_{s}-1}{R_{s}^{a}\left(\sum_{k} \ell_{k 0}\left(1-r_{k s}\right)\right)}<0
$$

That is, the hiring wage in $s$ is a decreasing function of the mean retention in $s$. In other words, the hiring wage is positively related to the total number of laid-off workers in the economy. It implies that wages for entrants fall as the state gets better. At the limit, if there is no lay-off in the end of the first period $\left(r_{k s}=1\right.$ for all $k$ ), then $w_{s}^{h}=0$ (remember that $\left.u^{\prime}(0)=+\infty\right)$. In this case, we will have $w_{j s}=t_{s}$, the solution obtained with the DCE. Of course, if there is no firing of unionized workers if a state $s$ is announced at the end of the first period, this insurance is obsolete and it is optimal to let the hiring wage fluctuate around its Walrasian level. When lay-off becomes more generalized, it appears that a partial insurance is needed. This feature can be interpreted in terms of labour mobility. Indeed, we can consider $\left(\sum_{k} \ell_{k 0} r_{k s}\right)^{-1}$ as an index for labour mobility. Then, inequality (20) expresses the property that the wage discrimination by hiring date is inversely related to the labour mobility. An industry with highly mobile workers will prefer to adopt a non-discriminated wage structure. In this context, the intergenerational wage scale discrimination is lessened and the usual implication is reversed: not only do non-discriminated wage scales allow high mobility but also higher labour mobility implies less discrimination.

(iii) There is nevertheless one problem with the hiring wage strategy. That is, the larger the hiring wage is, the smaller is the number of new recruits that prosperous firms will accept to hire. In case of large elasticity of the demand for labour, raising $w_{j s}$ can even reduce $w_{s}^{*}$. This is seen by totally differentiating equation (1):

$$
\frac{d w_{s}^{*}}{d w_{j s}}=\frac{\Phi_{j s}}{u^{\prime}\left(w_{s}^{*}\right)}\left[u^{\prime}\left(w_{j s}\right)-\left|\tilde{\eta}_{j s}\right| \frac{u\left(w_{j s}\right)-u\left(t_{s}\right)}{w_{j s}}\right],
$$

which can be either positive or negative. Now, laid-off union workers are interested in maintaining a high certainty equivalent wage $w_{s}^{*}$. In consequence, the trade union should prefer less wage discrimination, viz. larger hiring wages, when the elasticity of the demand for labour is small (in absolute value):

$$
\frac{\partial w_{s}^{h}}{\partial\left|\tilde{\eta}_{s}\right|}=-\frac{1+\frac{R_{s}^{r}}{2}}{R_{s}^{a}\left[1-\left|\tilde{\eta}_{s}\right|\left(1+\frac{R_{s}^{r}}{2}\right)\right]}<0 .
$$

In conclusion, the larger the elasticity of the demand for labour is, the more difficult it is to implement a good protection for workers. 
(iv) We have:

$$
\frac{\partial w_{s}^{h}}{\partial R_{s}^{r}}=-\frac{\left|\tilde{\eta}_{s}\right|}{\frac{2}{R_{s}^{a}\left[1-\left|\tilde{\eta}_{s}\right|\left(1+\frac{R_{s}^{r}}{2}\right)\right]}}<0 .
$$

This effect is connected with the previous on in the sense that raising $w_{j s}$ reduces the probability $\Phi_{j s}$ to be hired in firm j. It implies an increase of the risk borne by unemployeds during the "employment lottery" taking place at the beginning of period 2 . It has a negative effect on the expected utility of this lottery. This effect is worsened when the risk aversion of workers is large. So, a risk averse trade union has an incentive to increase the wage discrimination.

From this discussion and from equation (17), one can conclude that there exists only one particular situation in which the self-interested centralized trade union will prefer a totally non-discriminatory wage structure. The situation is characterized by two points: first, all unemployeds have to be members of the trade union $\left(q_{s}=1\right.$, i. e. there is no free rider with respect to insurance indemnities on the labour market) and, second, the elasticity of the demand for labour has to be zero.

To complete the analysis, we adress the following question: what is the best firing strategy for the first-period coalition employers-insiders? First, the "no-replacement" property of the decentralized cooperative equilibrium can easily be extended for this model with a centralized wage setting process; firms will not hire new recruits before employing all workers under contract in their own firm. Although there is cooperation among different firms, no worker of one firm will be sacrified to hire laid-off workers from another, for any wage differentials. Second, it can easily be shown that a declining industry will decide to fire union workers only when the marginal product of labour falls to $\operatorname{gCCE}\left(w_{j s}^{i}, w_{j 0}, w_{s}^{*}, y_{s}\right)$ :

$$
\begin{aligned}
f_{j s}^{\prime}\left(L_{j s}\right) & =g C C E\left(w_{j s}^{i}, w_{j 0}, w_{s}^{*}, \gamma_{s}\right) \\
& =g^{D C E}\left(w_{j s}^{i}, w_{j 0}, w_{s}^{*}\right)-\gamma_{s}^{-1} \frac{u\left(w_{j s}^{i}\right)-u\left(t_{s}\right)}{u^{\prime}\left(w_{j 0}\right)}-\gamma_{s}^{-1} \frac{u\left(w_{j s}\right)-u\left(t_{s}\right)}{u^{\prime}\left(w_{j 0}\right)},
\end{aligned}
$$

whenever $r_{i s}<1$. Comparing conditions (9) and (23), observe that, ceteris paribus, gCCE $<$ $g D C E$. It implies that the retention rate is larger in the CCE model than in the DCE. The idea of the result is that increasing the number of layoffs in one firm will raise the unemployment rate, thereby diminishing the probability of a representative unemployed to find a job. Contrary to the decentralized model in which this kind of interaction is not taken into account, a centralized union has an additional incentive to limit firings as much as possible in order to provide a higher probability $\sum_{k} \Phi_{k s}$ for previously laid-off union workers to find a job.

Remember that this analysis is in order in case of unemployment. When the unemployment rate tends to zero, the certainty equivalent wage $w_{s}^{*}$ tends to the hiring wage $w_{s}^{h}$ prevailing in the economy (see condition (13vii) when $\sum_{j} \Phi_{j s} \rightarrow 1$ ). Once full-employment is reached, $w_{s}^{*}$ becomes the well-known market clearing wage. Firms and trade unions are then obliged to adapt the hiring wage to the conditions imposed by the labour market: $w_{s}^{h}$ $=w_{s}^{*}$. As long as the state becomes better, the hiring wage rises, until it reaches the firstbest wage $\omega$. This evolution is depicted in Figure 3. 
Figure 3: Wages as a function of the employment rate

(Centralized cooperative equilibrium)

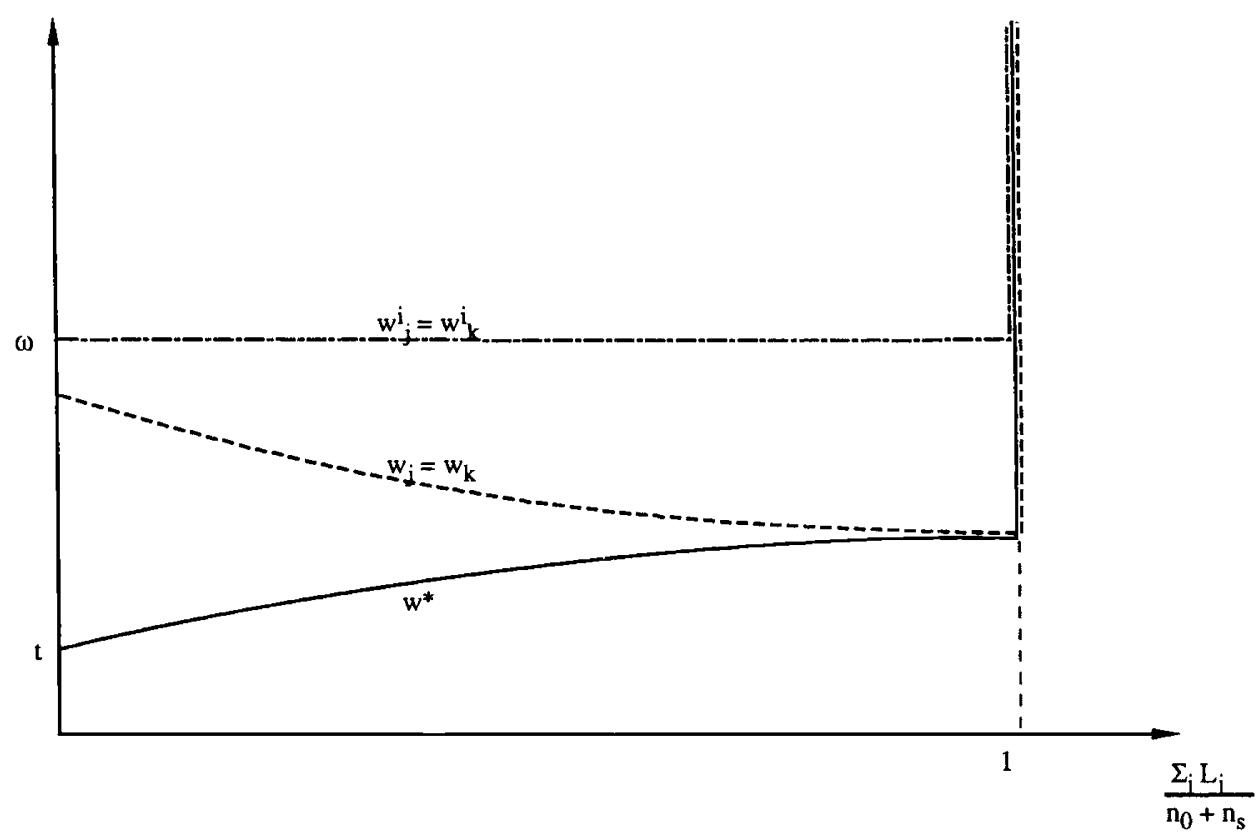

In summary, observe that a representative worker of generation 1 bears three kinds of risks (see figure 1). First is the risk to be employed by a firm offering unfavourable contracts, or to not be employed at all in the first period (i.e. to receive the reservation wage in the first period but also to have no opportunity to negotiate an insurance contract for the second period). This risk is unimportant in this model because the utility of contracts is assumed to be transferable.

The second risk comes form the uncertainty about the second period contractual wage and about the possibility to be fired. The treatment followed here is the usual, i.e. workers pay an insurance premium during the first period to be covered in the future against adverse realisations of the state of the world. The insurance coverage takes the form of a constant, contractual wage combined with overemployment in the second period. The incomplete character of the insurance (layoff risk) describes the best compromise between productive efficiency and risk sharing.

The third risk is to receive a low wage in another firm if the worker is laid off by the firm which employed him during the first period, or, if the worst comes to the worst, not to find any job at all. This risk is also partially covered by an insurance contract leading to a higher expected wage for laid-off workers. This is done by setting a higher tetention rate for declining firms, a higher hiring rate for prosperous firms and, last but not least, by offering a hiring wage above the reservation wage. 
As for the second risk, this is the trade-off between productive efficiency and risk sharing which implies that the "employment insurance" is only partial, saying that a laid-off worker is not sure to find another job. But while the "wage insurance" is complete for the second risk (a retained worker has no uncertainty about his wage), this is not the case here (a worker who finds a new job receives a wage $w_{s}$ less than $\omega$ ). The reason is that old workers are reluctant to share the benefit of their bargaining position with young workers of the second generation. If the young cohort size is too large, generation one will prefer not to insure this risk. Otherwise, the second generation will also be partially covered against bad realisations of the state of the world. The hiring wage and the employment rate are then decreasing functions of the cohort size of the generation entering the labour market. This is consistent with empirical observations (Bloom and Freeman [1986]).

Finally, a partial wage flexibility emerges in this framework. Wage scales will be fully flexible in periods of low mobility: hiring wages will respond to any disequilibrium on the labour market. In periods of industrial reorganization and high mobility, hiring wage rigidity will be the rule. Specifically, there will be no discrimination by hiring date in that case. This seems to be consistent with empirical observations. As a matter of fact, Dewatripont [1986] tests a relation between the proportion of workers covered by two-tier contracts in a sector and several independent variables characterizing this sector, such as the turnover rate, the unemployment rate or the unemployment growth in the U.S. The results provide some support for this model: the discrimination by hiring dates tends to increase in periods of low unemployment rate. The variable is significant. In his mind, the reason is that twotier contracts are harder to sell to workers, since it introduces inferior treatment not only for newcomers but also for workers who are on temporary layoff, and vote on the contract. This is conceptually the same interpretation as mine. Moreover, it is perhaps not uninteresting to note that the timing of two-tier contracts is also consistent with the CCE model. Such contracts appeared with the economy recovery.

\section{Paternalistic trade union}

Obviously, the selfish union assumption used so far is a pessimistic and unfair assumption. Trade unions are concerned about (youth) unemployment. It seems that they are rather reluctant to introduce wage discriminations by hiring dates among their members. Fathers want to offer good job opportunities to their children. In this section, I analyze the case of a benevolent union which brings together either present workers and workers-to-be. When the union negotiates with firms to elaborate an agreement about present and future wage rates, it not only represents the interest of current workers but it also stands up for current unemployeds and future generations. As a benchmark, I assume that the central union uses an egalitarian objective function $V$ where

$$
V=\sum_{j} \ell_{j 0} U\left(C_{j}, w^{*}\right)+\left(n_{0}-\sum_{j} \ell_{j 0}\right)\left(u\left(t_{0}\right)+\delta E_{s} u\left(w_{s}^{*}\right)\right)+\delta E_{s}\left[n_{s} u\left(w_{s}^{*}\right)\right]
$$

Since the union gives the same weight to all individuals, $V$ is simply the sum of the discounted expected utility of workers for the two periods: there are $\ell_{j 0}$ workers hired by firm $\mathrm{j}, \mathrm{j}=1, \ldots, \mathrm{J}$, receiving $U\left(C_{j}, w^{*}\right)$. The $\left(n_{0}-\sum_{j} \ell_{j 0}\right)$ remaining unemployeds of the first generation only get $\left(u\left(t_{0}\right)+\delta E_{s} u\left(w_{s}^{*}\right)\right)$ as discounted expected utility. Finally, the $n_{s}$ young workers entering into the labour market in period 2 , state s, can expect a discounted expected utility $\delta u\left(w_{s}^{*}\right)$. 
Except for the trade union objective, I will use exactly the same bargaining structure as in section 4 , that is cooperate behaviour and centralized wage setting mechanism. The program then reads:

$$
\begin{aligned}
& \max _{C, \ell, w, w^{*}} \lambda_{1} \sum_{j}\left[\Pi_{j 0}+\delta E\left[\Pi_{j s}\right]\right]+\lambda_{2} V \\
& \text { subject to }(13 i), \ldots,(13 v i i i)
\end{aligned}
$$

Technical details about the derivation of this optimum are relegated to Appendix C. The point is that Proposition 3 and the Corollary may be used again, providing that both $\gamma_{s}$ and $q_{s}$ be redefined as

$$
\begin{gathered}
\gamma_{s}=\frac{\phi_{s}-\sum_{k \in K} \ell_{k s}\left[u^{\prime}\left(w_{s}^{*}\right)+\tilde{\eta}_{k s} \frac{u\left(w_{s}^{*}\right)-u\left(t_{s}\right)}{w_{s}^{*}}\right]}{\phi_{s}-u^{\prime}(\omega) \sum_{k \in K_{s}} L_{k s}} \\
q_{s}=1
\end{gathered}
$$

Since $\phi_{s}$ is the total number of unemployeds at the beginning of period 2 , it is larger than $\sum_{j} \ell_{j 0}\left(1-r_{j s}\right)$ which is the number of unemployeds having participated to the constitution of the insurance reserve. It implies that the new $\gamma_{s}$ is smaller than the one defined in the previous section. From equation (16), there results ceteris paribus a larger hiring wage in period 2. As expected, a paternalistic trade union will impose a smaller wage discrimination than a self-interested one. This comes from the fact that the trade union is interested in insuring future generations against economic slumps. The insurance premium paid by the first-period workers will also cover unemployeds and workers-to-be. Insiders are not any more reluctant to share benefits of the wage-insurance they paid for with outsiders.

In the simplified case with firm-independent $\tilde{\eta}_{j s}$, the hiring wage is characterized by:

$$
u^{\prime}\left(w_{s}^{h}\right)=u^{\prime}(\omega)+\left|\tilde{\eta}_{s}\right| \frac{u\left(w_{s}^{h}\right)-u\left(t_{s}\right)}{w_{s}^{h}}
$$

One can easily interpret equation (28) by analyzing the impact of an increase $\Delta w_{j s}>0$ of the hiring wage. It generates an improvement of welfare $l_{j s} u^{\prime}\left(w_{j s}\right) \Delta w_{j s}$, but it increases wage costs for the firm by $l_{j s} \Delta w_{j s}$. Finally, the firm adapts its hiring decision by reducing the number of newcomers: $\Delta l_{j s}=\bar{\eta}_{s} l_{j s} \Delta w_{j s} / w_{j s}<0$. At the margin, it has no effect on profits. Instead, there is a loss in welfare due to the fact that $\left|\Delta l_{j s}\right|$ additional workers are involuntary unemployed. The aggregate loss amounts $\left[u\left(w_{s}^{h}\right)-u\left(t_{s}\right)\right] \Delta l_{j s}$. At the optimum, weighted gains and losses compensate each other:

$$
\lambda_{2} l_{j s} u^{\prime}\left(w_{j s}\right) \Delta w_{j s}=\lambda_{1} l_{j s} \Delta w_{j s}+\lambda_{2}\left|\tilde{\eta}_{s}\right| \frac{l_{j s}}{w_{j s}}\left[u\left(w_{s}^{h}\right)-u\left(t_{s}\right)\right] \Delta w_{j s}
$$

or equivalently, 


$$
u^{\prime}\left(w_{s}^{h}\right)=\frac{\lambda_{1}}{\lambda_{2}}+\left|\tilde{\eta}_{s}\right| \frac{u\left(w_{s}^{h}\right)-u\left(t_{s}\right)}{w_{s}^{h}}
$$

which corresponds to equation (28) using condition (14). The following formula (previously obtained by Drèze [1986], Appendix) holds as an approximation:

$$
\frac{u^{\prime}\left(w_{s}^{h}\right)-u^{\prime}\left(w_{j s}^{i}\right)}{u^{\prime}\left(w_{s}^{h}\right)}=\left|\tilde{\eta}_{s}\right|\left(1+\frac{R_{s}^{r}}{2}\right),
$$

so the hiring wage is independent of the cohort size $n_{s}$ entering the labour market at that time. It is also independent of the actual economic environment measured by the total number of layoffs in the economy $\sum_{j} \ell_{j 0}\left(1-r_{j s}\right)$. In this sense, the new equilibrium exhibits a downward hiring wage rigidity combined with an intermediary wage discrimination. In bad states, the hiring wage does not fall until $t_{s}$. Instead, once the level of wage discrimination implicitly defined by (28) is reached, the hiring wage is stabilized by a cooperative action of firms and trade unions. It implies the early appearance of unemployment. The wage discrimination is due to the fact that the hiring wage rate influences negatively the hiring rate, whereas the wage for insiders does virtually not influence their employment level, because of the labour hoarding implicit agreement with firms. It induces the trade union to propose a smaller wage for new recruits in order to reduce unemployment. In fact, the accepted level of discrimination is a best compromise between earnings and unemployment risks, given the elasticity of the demand for labour and the attitude towards risks. From (28), it is only when the elasticity of the demand for labour vanishes that there will be no discrimination at all at equilibrium.

\section{Conclusion}

The implicit labour contract literature does not explain why modern capitalist economies are confronted to a prolonged mass enemployment problem since the beginning of the 1970s. The theory in print does not deal with disequilibrium on the labour market. In this paper, I tried to find an adequate description of the labour market that would explain the prevalance of involuntary unemployment, and in particular youth unemployment.

Successive generations have been introduced in a two-period model. For the two first models, the fundamental idea is that future generations are not represented when the initial labour contracts are drawn. They are not able to agree with firms about an insurance labour contrat specifying the compensation and the terms of employment simultaneously for recession and boom conditions of the future. In this sense, trade unions represent the interests of the currently employeds alone. Wage and employment negotiations taking place in the first period do not take into account the presence of generations entering the labour market in the future. These groups are in no position to argue.

It has been widely argued in particular (see for example Blanchard and Summers [1986]) that an increase in aggregate demand will lead self-interested unions to demand higher wages rather than higher output and employment. But increasing wages for insiders is not necessarily incompatible with an efficient level of employment if a discrimination by hiring date is allowed. This is shown in the DCE model. Specifically, new recruits could be paid wages that clear the labour market while previously employed workers would keep 
wages at their level determined by contracts. In recession periods, unions can cut firms' wage costs, and thus protect jobs, without accepting lower pay or harder work. They simply agree to wage cuts for workers-to-be. This explains the widespread generalization of twotier schemes in the United States since 1983. The DCE model seems to fit well the American economic environment.

To the contrary, European countries are highly unionized. Moreover, in most countries, collective bargainings that matter are on a national, regional or sectoral basis. This could explain the relatively limited two-tiers scheme phenomenon in Europe. As a matter of fact, the CCE model exhibits a smaller wage discrimination by hiring date; the discrimination being a decreasing function of the labour mobility. The idea behind this result is that unionized workers want to insure against getting a badly paid job after being fired from another firm.

It is finally shown that even a paternalistic trade union will not aim at a non discriminatory wage structure. Nevertheless, old generations will protect young workers against variations of the hiring wage. This wage is fixed at a lower level than the one for older generations in order to limit the unemployment rate for the young cohort. Risk sharing arrangements among different vintages of workers are constrained by the productive inefficiencies induced by the wage rigidity. It remains that a paternalistic trade union will impose less wage discrimination than a self-interested one. From this discussion, it clearly results that the wage discrimination emerging in this model is the expression of the inability of future generations to obtain forward labour contracts with job security and earning insurance: when they arrive into the labour market, they are without any protection, whereas older workers have constituted an insurance reserve which will finance larger senior wages in bad states.

A solidarity principle as analyzed in this latter framework is shown to be not sufficient to claim for a non-discriminatory wage structure. In conclusion, the paper has been organized in a way to exhibit less and less discrimination when going from section 3 to 5: maximal discrimination with a decentralized wage setting procedure, intermediary wage discrimination in a centralized procedure with self-interested generations, and even less discrimination in the case of a centralized paternalistic union.

As a final remark, the above analysis neglects the "fairness issue": much of the controversy generated by two-tier contracts stems from the departure they represent from egalitarian policies. A wage discrimination by hiring date goes against the grain of accepted ethical norms, because it introduces pay differences for equal work. In England for example, the principle of "equal pay for equal value work" is embodied in the Equal Pay Act, 1970. Whilst this act was primarily designed to prevent discrimination against women, a new recruit hired at a lower rate could sue an employer by appeal to it. 


\section{Appendix A (DCE model)}

Taking equation (7) as a constraint in program (6) and including $w^{*}$ as a decision variable in the model implies that the first-order conditions of the problem of firm $j$ read:

$$
\forall s:
$$

$$
\begin{aligned}
& w_{j s}^{i}=\max \left(w_{j 0}, w_{j s}\right) \\
& f_{j s}^{\prime}\left(L_{j s}\right)-w_{j s}^{i}+\frac{u\left(w_{j s}^{i}\right)-u\left(w_{s}^{*}\right)}{u^{\prime}\left(w_{j 0}\right)}+\frac{\mu_{j s} \phi_{s}^{-1}}{\delta p_{s} \lambda_{1 j}}\left(u\left(w_{s}^{*}\right)-u\left(t_{s}\right)\right)=\rho_{j s} \\
& \text { with } \rho_{j s} \begin{cases}\leq 0, & \text { if } r_{j s}=0 \\
=0, & \text { if } 0<r_{j s}<1 \\
\geq 0, & \text { if } r_{j s}=1\end{cases}
\end{aligned}
$$

where $f_{j s}^{\prime}$ is the marginal value product of labour of firm $j$, state $s$. It is a function of the total employment $L_{j s} . \mu_{j s}$ is the dual variable for constraint (7).

To prove Proposition 1, we first derive Lemma 1 which indicates that it will never be efficient to replace insiders by outsiders, whatever the wage discrimination is.

Lemma 1: In the decentralized cooperative model, it is never efficient for the coalition of the firm and its union to hire new workers if some seasoned workers are laid off, i.e. $l_{j s}=0$ whenever $r_{j s}<1$.

Proof: Suppose that there exists a couple $j$, s such that $l_{j s}>0$ and $r_{j s}<1$. From (A2) and (A4), this implies that 


$$
\begin{aligned}
f_{j s}^{\prime} & =w_{j s}-\frac{\mu_{j s} \phi_{s}^{-1}}{i p_{s} \lambda_{1 j}}\left[u\left(w_{j s}\right)-u\left(t_{s}\right)\right] \\
& \leq w_{j s}^{i}-\frac{u\left(w_{j s}^{i}\right)-u\left(w_{s}^{*}\right)}{u^{\prime}\left(w_{j 0}\right)}-\frac{\mu_{j s} \phi_{s}^{-1}}{i p_{s} \lambda_{1 j}}\left[u\left(w_{s}^{*}\right)-u\left(t_{s}\right)\right]
\end{aligned}
$$

This necessary condition can be rewritten as

$$
w_{s j} \leq w_{j s}^{i}-\frac{u\left(w_{j s}^{i}\right)-u\left(w_{s}^{*}\right)}{u^{\prime}\left(w_{j 0}\right)}+\frac{\mu_{j s} \phi_{s}^{-1}}{i p_{s} \lambda_{1 j}}\left[u\left(w_{j s}\right)-u\left(w_{s}^{*}\right)\right]
$$

Consider now two cases:

i) $w_{j s}=w_{s}^{*}$. In that case, the inequality will be verified only if $w_{j s}^{i}=w_{s}^{*}$. This is a contradiction because $l_{j s}\left(1-r_{j s}\right)=0$ whenever $w_{j s}=w_{s}^{*}=w_{j s}^{i}$.

ii) $w_{j s}>w_{s}^{*}$. Here, $\mu_{j s} \geq \frac{\delta p_{s} \lambda_{1 j}}{\phi_{s}^{-1} u^{\prime}\left(w_{j s}\right)}$ from the condition (A7). Therefore the inequality becomes

$$
\begin{aligned}
w_{j s} & \leq w_{j s}^{i}-\frac{u\left(w_{j s}^{i}\right)-u\left(w_{s}^{*}\right)}{u^{\prime}\left(w_{j 0}\right)}+\frac{u\left(w_{j s}\right)-u\left(w_{s}^{*}\right)}{u^{\prime}\left(w_{j s}\right)} \\
& \leq w_{j s}^{i}-\frac{u\left(w_{j s}^{i}\right)-\left[k_{j s} u\left(w_{j s}\right)+\left(1-k_{j s}\right) u\left(w_{s}^{*}\right)\right]}{u^{\prime}\left(w_{j 0}\right)}
\end{aligned}
$$

where $k_{j s}=\frac{u^{\prime}\left(w_{j 0}\right)}{u^{\prime}\left(w_{i s}\right)}$. Because the second term in the RHS of the last inequality is strictly positive, one can observe that $w_{j s}<w_{j s}^{i}$. By condition (A1), $w_{j s}^{i}=w_{j 0}>w_{j s}$. This implies that $k_{j s}$ is less than 1 . Therefore, the term $\left[k_{j s} u\left(w_{j s}\right)+\left(1-k_{j s}\right) u\left(w_{s}^{*}\right)\right]$ is less than $u\left(w_{j s}\right)$. Finally, the necessary condition is

$$
w_{j s} \leq w_{j 0}-\frac{u\left(w_{j 0}\right)-u\left(w_{j s}\right)}{u^{\prime}\left(w_{j 0}\right)}
$$

Using a second-order Taylor expansion around $w_{j 0}$ to evaluate $u\left(w_{j s}\right)$, the last inequality implies that

$$
w_{j s} \leq w_{j s}+\frac{\left(w_{j s}-w_{0}\right)^{2}}{2} \frac{u^{\prime \prime}\left(\xi_{j s}\right)}{u^{\prime}\left(w_{j 0}\right)} \leq w_{j s}, \quad w_{j s} \leq \xi_{j s} \leq w_{j 0},
$$

the last inequality coming from the risk aversion assumption. Hence, the necessary condition is verified only if all inequalities are replaced by equalities, i. e. if $w_{j s}^{i}=w_{j s}=w_{s}^{*}$, a contradiction because we assumed here $w_{j s}>w_{s}^{*}$.

The proof of Proposition 1 then follows easily: suppose that there exists a couple $j, s$ such that $w_{j s}>w_{s}^{*}$. Then, the combination of (A7) and (A8) implies that

$$
\mu_{j s}=i p_{s} \lambda_{2 j} l_{j 0}\left(1-r_{j s}\right) \geq \frac{\delta p_{s} \lambda_{1 j}}{\phi_{s}^{-1} u^{\prime}\left(w_{j s}\right)}
$$

Because the RHS of the inequality is strictly positive, it is necessary to have $r_{j s}<1$. Then, by proposition $1, \ell_{j s}=0$. The last point is to see that if $\ell_{j s}$ vanishes whenever $w_{j s}>w_{s}^{*}$, then $w_{s}^{*}$ equals $\mathrm{t}_{\mathrm{s}}$ by definition of $w_{s}^{*}$. This concludes the proof. 


\section{Appendix B (CCE model)}

The first-oder necessary conditions for program (13) are:

$$
\forall j, s \text { : }
$$

$$
\begin{aligned}
&-\delta p_{s} \lambda_{1} \ell_{j 0} r_{j s}+\delta p_{s} \lambda_{2} \ell_{j 0} r_{j s} u^{\prime}\left(w_{j s}^{i}\right)+\beta_{j s}=0 \\
& \text { with } \beta_{j s} \quad\left\{\begin{array}{lll}
\geq 0 & \text { if } & w_{j s}^{i}=w_{j s} \\
=0 & \text { if } & w_{j s}^{i}>w_{j s}
\end{array}\right.
\end{aligned}
$$

$$
R_{j s}^{\prime}-w_{j s}^{i}+\frac{u\left(w_{j s}^{i}\right)-u\left(w_{s}^{*}\right)}{u^{\prime}\left(w_{j 0}\right)}+\frac{\mu_{s} \phi_{s}^{-1}}{\delta p_{s} \lambda_{1}}\left(u\left(w_{s}^{*}\right)-u\left(t_{s}\right)\right)+\frac{\xi_{j s} R_{j s}^{\prime \prime} \ell_{j s}}{\delta p_{s} \lambda_{1}}=\rho_{j s}+\psi_{s}
$$

$$
\text { with } \rho_{j s}\left\{\begin{array}{lll}
\leq 0, & \text { if } & r_{j s}=0 \\
=0, & \text { if } & 0<r_{j s}<1 \\
\geq 0, & \text { if } & r_{j s}=1
\end{array}\right.
$$

$$
R_{j 0}^{\prime}\left(l_{j 0}^{o l d}+l_{0}\right)-w_{j 0}+\delta E_{s}\left[r_{j s}\left[\rho_{j s}-\frac{u\left(w_{j s}^{i}\right)-u\left(w_{s}^{*}\right)}{u^{\prime}\left(w_{j 0}\right)}\right]\right]=\psi_{0}-\frac{U\left(C_{j}, w^{*}\right)}{u^{\prime}\left(w_{j 0}\right)}
$$

$$
\text { where } \psi_{0}\left\{\begin{array}{lll}
\geq 0 & \text { if } & \sum_{j} l_{j 0}=n_{0} \\
=0 & \text { if } & \sum_{j} l_{j 0}<n_{0}
\end{array}\right.
$$

$$
f_{j s}^{\prime}\left(L_{j s}\right)-w_{j s}+\frac{\mu_{s} \phi_{s}^{-1}}{\delta p_{s} \lambda_{1}}\left(u\left(w_{j s}\right)-u\left(t_{s}\right)\right)+\frac{\xi_{j s}\left(f_{j s}^{\prime}-w_{j s}+f_{j s}^{\prime \prime} \ell_{j s}\right)}{\delta p_{s} \lambda_{1}}=\zeta_{j s}+\psi_{s}
$$

$$
\text { with } \zeta_{j s} \quad\left\{\begin{array}{lll}
\leq 0 & \text { if } & \ell_{j s}=0 \\
=0 & \text { if } & \ell_{j s}>0
\end{array}\right.
$$

$u^{\prime}\left(w_{j 0}\right)=\frac{\lambda_{1}}{\lambda_{2}}$

6)

$$
w_{j s}^{i}=w_{j s}=w_{s}^{*} \Rightarrow l_{j s}\left(1-r_{j s}\right)=0
$$$$
-\delta p_{s} \lambda_{1} \ell_{j s}+\mu_{s} \phi_{s}^{-1} \ell_{j s} u^{\prime}\left(w_{j s}\right)-\xi_{j s} \ell_{j s}+\alpha_{j s}-\beta_{j s}=0
$$$$
\text { where } \alpha_{j s}\left\{\begin{array}{lll}
\geq 0 & \text { if } & w_{j s}=w_{s}^{*} \\
=0 & \text { if } & w_{j s}>w_{s}^{*}
\end{array}\right.
$$

Next, we prove Proposition 3 by rearranging conditions (B4), (B7), and (B8).

Proof of Proposition 3: For $k \in K_{s}$, it follows from (B7) that

$$
\alpha_{k s}=\xi_{k s} \ell_{k s}+\delta p_{s} \lambda_{1} \ell_{k s}-\mu_{s} \phi_{s}^{-1} \ell_{k s} u^{\prime}\left(w_{k s}\right) .
$$


If $\ell_{k s}>0$, we obtain from (13viii) and (B4) that

$$
\xi_{k s}=-\mu_{s} \phi_{s}^{-1} \tilde{\eta}_{k s} \frac{u\left(w_{k s}\right)-u\left(t_{s}\right)}{w_{k s}}
$$

whenever some unemployment remains. By combining (B9) and (B10), it results

$$
\alpha_{k s}=-\mu_{s} \phi_{s}^{-1} \ell_{k s}\left[u^{\prime}\left(w_{k s}\right)+\tilde{\eta}_{k s} \frac{u\left(w_{k s}\right)-u\left(t_{s}\right)}{w_{k s}}\right]+\delta p_{s} \lambda_{1} \ell_{k s} .
$$

Noting that $\alpha_{j s}=0$ when $j € K_{s}$, condition (B8) may now be written again as

$$
\delta p_{s} \lambda_{2} \sum_{j} l_{j 0}\left(1-r_{j s}\right)-\delta p_{s} \lambda_{1} \sum_{k \in K_{s}} \ell_{k s}=\mu_{s}\left[1-\phi_{s}^{-1} \sum_{k \in K_{s}} \ell_{k s}\left[u^{\prime}\left(w_{k s}\right)+\tilde{\eta}_{k s} \frac{u\left(w_{k s}\right)-u\left(t_{s}\right)}{w_{k s}}\right]\right] \text {. }
$$

By definition of $\gamma_{s}$, this equation implies that

$$
\mu_{s}=\delta p_{s} \lambda_{2} \phi_{s} \gamma_{s}^{-1}
$$

Suppose now that there exists a $\mathrm{j}$ such that $w_{s}^{*}<w_{j s}<w_{j s}^{i}$ at equilibrium. This implies that $\alpha_{j s}=\beta_{j s}=0$. Then, substituting $\mu_{s}$ in (B7) by its expression given by equation (B12) yields

$$
\ell_{j s}\left[-\delta p_{s} \lambda_{1}+\delta p_{s} \lambda_{2} \gamma_{s}^{-1} u^{\prime}\left(w_{j s}\right)-\xi_{j s}\right]=0 .
$$

To conclude, if $\ell_{j s}=0$, one can arbitrarily impose $w_{j s}=w_{j s}^{h}$. Otherwise, using equations (B5), (B10), (B12) and (B13) yields

$$
\begin{aligned}
u^{\prime}\left(w_{j s}\right) & =\frac{\gamma_{s}}{\delta p_{s} \lambda_{2}}\left[\delta p_{s} \lambda_{1}+\xi_{j s}\right] \\
& =\gamma_{s}\left[u^{\prime}(\omega)-\frac{\mu_{s} \phi_{s}^{-1} \tilde{\eta}_{j s}}{\delta p_{s} \lambda_{2}} \frac{u\left(w_{j s}\right)-u\left(t_{s}\right)}{w_{j s}}\right] \\
& =\gamma_{s} u^{\prime}\left(\omega+\left|\tilde{\eta}_{j s}\right| \frac{u\left(w_{j s}\right)-u\left(t_{s}\right)}{w_{j s}}\right.
\end{aligned}
$$

This is just equation (15). Hence $w_{j s}=w_{j s}^{h}$ whenever $w_{s}^{*}<w_{j s}<w_{j s^{*}}^{i}$

Proof of the Corollary: If $\tilde{\eta}_{j s}$ is independent of $\mathrm{j}$, it implies by (16) that $w_{j s}^{h}$ is also independent of $\mathrm{j}$. Let us denote it by $w_{s}^{h}$.

Suppose first that $w_{s}^{h}$ is larger than $w_{s}^{*}$, so we have $w_{j s}>w_{s}^{*}$. It result that $K_{s}=\emptyset$ and $\gamma_{s}$ equals $q_{s}^{-1}$. It follows that condition (16) may be written again as condition (17). Moreover, $w_{s}^{h}$ is always smaller than $\omega$ since.

$$
u^{\prime}\left(w_{s}^{h}\right)=u^{\prime}(\omega) q_{s}^{-1}+\left|\tilde{\eta}_{s}\right| \frac{u\left(w_{s}^{h}\right)-u\left(t_{s}\right)}{w_{s}^{h}} \geq u^{\prime}(\omega) q_{s}^{-1} \geq u^{\prime}(\omega)
$$


The first inequality comes from the assumption that $w_{s}^{h}>w_{s}{ }^{*}$, this latter variable being larger than $t_{s}$ by construction. The second inequality is due to the fact that $q_{s}$ is a proportion, so it is always smaller than unity. By the risk-aversion assumption, (B15) implies that $w_{s}^{h} \leq$ $\omega$. Confronting equations (14), (15) and (B1) yields both $w_{j s}^{i}=\omega$ and $w_{j s}=w_{s}^{h}$.

Alternatively, assume that $w_{s}^{h}<w_{s}^{*}$. In such case, equation (15) implies that $w_{j s}=w_{s}^{*}$ $\forall j$. Using equation (1), we have that $\left(1-\sum_{j} \Phi_{j s}\right) u\left(\mathrm{w}_{\mathrm{s}}^{*}\right)=\left(1-\sum_{j} \Phi_{j s}\right) u\left(t_{s}\right)$, thereby implying the equality $w_{s}^{*}=t_{s}$ at equilibrium. This concludes the proof.

\section{Appendix C (Paternalistic model)}

The necessary conditions for program (25) differ from (B1)-(B8) by conditions (B3) and (B8) which may be rewritten as:

(B3') $f_{j 0}^{\prime}\left(l_{j 0}^{l o l d}+l_{j 0}\right)-w_{j 0}+\frac{U\left(C_{j}, w^{*}\right)-U^{u}\left(w^{*}\right)}{u^{\prime}\left(w_{j 0}\right)}+\delta E_{s}\left[r_{j s}\left[\rho_{j s}-\frac{u\left(w_{j s}^{i}\right)-u\left(w_{s}^{*}\right)}{u^{\prime}\left(w_{j 0}\right)}\right]\right]=\psi_{0}+\psi_{\mathrm{s}}$,

and

$$
\delta p_{s} \lambda_{2} \phi_{\mathrm{s}}=\mu_{s}+\sum_{j} \alpha_{j s}
$$

where $U^{u}$ is the discounted expected utility of a worker who has not find a job in period 1 , i.e.

$$
U^{u}\left(w^{*}\right)=u\left(t_{0}\right)+\delta E_{s} u\left(w_{s}^{*}\right)
$$

The arguments contained in Appendix B can be used here to restate Proposition 3 and Corollary 1 with $\gamma_{s}$ defined by equation (26) and $q_{s}=1$. 


\section{REFERENCES}

AZARIADIS, C., [1975]: "Implicit contracts and underemployment equilibria", Journal of Political Economy, 83, 1183-1202.

BAILY, M. N., [1974]: “Wages and employment under uncertain demand", Review of Economic Studies, 41, 37-50.

BLANCHARD, O. J. and SUMMERS, L. H., [1986]: "Hysteresis and the European unemployment problem", Harvard Institute of Economic Research Discussion Paper No. 1240, Cambridge.

BLOOM, D.E. and FREEMAN, R. B., [1986]: “The youth problem: age or generational crowding?", NBER Working Paper Series 1829, Cambridge.

CARRUTH, A. A. and OSWALD, A. J., [1986]: "On union preferences and labour market models: insiders and outsiders", Center for Labour Economics Discussion Paper 256, London.

DEBREU, G., [1959]: Theory of value, Cowles Foundation Monograph 17, Yale University Press, New Haven.

DEWATRIPONT, M., [1986]: “Two-tier contracts as labor market adjustment”, DULBEA Working Paper 860, Bruxelles.

DRĖZE, J., [1986]: “Work-sharing: some theory and recent European experience”, Economic Policy, $1,561-620$.

DREZZE, J., [1981]: "Inferring risk tolerance from deductibles in insurance contracts", The Geneva Papers on Risk and Insurance, 6, 48-52.

GOLLIER, C., [1987]: “The role of wage setting in entry-deterrence”, CORE DP8717, Louvain-LaNeuve.

HOLMSTROM, B., [1983]: "Equilibrium long term contracts", Quarterly Journal of Economics, Supplement, 98, 23-54.

HORN, H. and SVENSSON, L.E. O., [1986]: "Trade unions and optimal labour contracts", The Economic Journal, 96, 323-341.

LEROY, R., [1987]: "Le salaire des jeunes est-il flexible? Belgique, 1955-1984, ouvriers", Bulletin de I'IRES No. 116, Louvain-La-Neuve.

LINDBECK, A. and SNOWER, D., [1984a]: "Involuntary unemployment as an insider-outsider dilemma", IIES Seminar Paper 282, Stockholm.

LINDBECK, A. and SNOWER, D., [1984b]: "Labour turnover, insider morale and involuntary unemployment", IIES Seminar Paper 310, Stockholm.

LINDBECK, A. and SNOWER, D., [1985a]: “Cooperation, harassement, and involuntary unemployment", IIES Seminar Paper 321, Stockholm.

LINDBECK, A. and SNOWER, D., [1985b]: "Wage setting, unemployment, and insider-outsider relations", IIES Seminar Paper 344, Stockholm.

SOLOW, R. M. , [1985]: "Insiders and outsiders in wage determination", Scandinavian Journal of Economics, 8, 411-428. 